\title{
Peripheral endocannabinoid concentrations are not associated with verbal memory impairment during MDMA intoxication
}

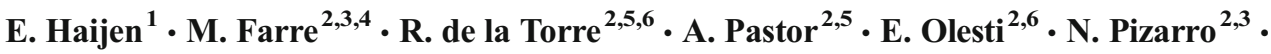 \\ J. G. Ramaekers ${ }^{1}$ - K. P. C. Kuypers ${ }^{1}$
}

Received: 29 May 2017 / Accepted: 7 November 2017 /Published online: 16 November 2017

(C) The Author(s) 2017. This article is an open access publication

\begin{abstract}
Background Preclinical data have suggested involvement of the endocannabinoid (eCB) system in MDMA-induced memory impairment. Clinical research has shown that blockade of the 5- $\mathrm{HT}_{2}$ receptor nulls memory impairment during MDMA intoxication. Interestingly, studies have demonstrated that the $\mathrm{eCB}$ and the 5HT system interact. It was hypothesized that MDMA would cause an increase in $\mathrm{eCB}$ concentrations together with a decrease in memory performance, and that combining MDMA with a 5$\mathrm{HT}_{2}$ receptor blocker ketanserin would lead to a counteraction of the MDMA effects on eCB concentrations and memory.

Methods Twenty healthy recreational polydrug users entered a double-blind placebo-controlled within-subject study. Participants received a pre-treatment (ketanserin $40 \mathrm{mg}$, placebo) followed 30 min later by a treatment (MDMA $75 \mathrm{mg}$, placebo). Verbal memory was tested by means of a 30 -word learning test. Endocannabinoid concentrations (anandamide (2-AG); $\mathrm{N}$ arachidonylethanolamine (AEA)) were assessed in blood at
\end{abstract}

K. P. C. Kuypers

k.kuypers@maastrichtuniversity.nl

1 Department of Neuropsychology and Psychopharmacology, Faculty of Psychology and Neuroscience, Maastricht University, Maastricht, The Netherlands

2 Integrative Pharmacology \& Neurosciences Systems Research Group, Institut Hospital del Mar d'Investigacions Mèdiques, Barcelona, Spain

3 Universitat Autonoma de Barcelona, Barcelona, Spain

4 Clinical Pharmacology, Hospital Universitari Germans Trias i Pujol, Badalona, Spain

5 Spanish Biomedical Research Centre in Physiopathology of Obesity and Nutrition (CIBEROBN), Santiago de Compostela, Spain

6 Universitat Pompeu Fabra, CEXS-UPF, Barcelona, Spain baseline, before (90 min post-treatment) and after cognitive tests (150 min post-treatment).

Results Findings showed that MDMA impaired memory 90 min post-treatment in the word learning task. This effect was a replication of previous studies using the same dose of MDMA (75 mg) and the same learning paradigm. Contrary to our hypothesis, MDMA did not affect eCB concentrations, nor did ketanserin block MDMA-induced memory impairment. Ketanserin caused an increase in AEA concentrations, 180 min after administration.

Conclusion Current findings suggest that peripherally measured endocannabinoids are not associated with the verbal memory deficit during MDMA intoxication. Trial registration number: NTR3691.

Keywords MDMA - Verbal memory - 5-HT2 receptor . Ketanserin $\cdot$ Endocannabinoids $\cdot 2$-AG $\cdot$ AEA

\section{Introduction}

Previous placebo-controlled experimental studies have consistently shown that a single dose $(75 \mathrm{mg})$ of (R,S)-3,4 methylenedioxymethamphetamine (MDMA) impairs memory for verbal information (e.g., de Sousa Fernandes Perna et al. 2014; Kuypers and Ramaekers 2005). The neurobiological mechanism underlying this impairment has been studied and it was suggested that the MDMA-induced elevation in plasma cortisol concentrations was not related to the observed deficit (Kuypers et al. 2013). van Wel and colleagues demonstrated that blockade of the serotonin-2A $\left(5-\mathrm{HT}_{2 \mathrm{~A}}\right)$ receptor, by means of a single dose of ketanserin, prevented the memory impairment after a single dose of MDMA (van Wel et al. 2011). The detailed neurobiological mechanism behind the MDMA-induced memory deficit has yet to be elucidated. 
There is evidence suggesting that the serotonergic neurotransmission system is modulated by the endocannabinoid (eCB) system. Specifically, the $\mathrm{CB}_{1}$ receptor modulates the excitability of dorsal raphe serotonin neurons (Haj-Dahmane and Shen 2011), and more relevant in the context of the findings by van Wel et al. (2011), 5- $\mathrm{HT}_{2 \mathrm{~A}}$ receptor activation stimulates the formation and release of 2-arachidonoylglycerol (2-AG), an endocannabinoid (Parrish and Nichols 2006). The best characterized eCBs are 2AG and AEA ( $N$-arachidonylethanolamine, anandamide), and both of these lipids exert agonist activity at $\mathrm{CB}_{1}$ and $\mathrm{CB}_{2}$ receptors. They are synthetized on an "on-demand" basis and crucial in certain forms of neuronal plasticity (Curran et al. 2016). Since MDMA acts on the 5- $\mathrm{HT}_{2 \mathrm{~A}}$ receptor (Erritzoe et al. 2011; van Wel et al. 2011), it can be hypothesized that this also has implications for endocannabinoid concentrations.

Converging data suggest that MDMA and (exogenous and endogenous) cannabinoids interact pharmacologically (Valverde and Rodriguez-Arias 2013). Both MDMA-induced conditioned place preference and self-administration in rats are under endogenous tonic control by the endocannabinoid system (Braida et al. 2005; Braida and Sala 2002). Low doses of THC have been demonstrated to modulate MDMA-induced behavioral effects, decreasing conditioned place preference (Robledo et al. 2007). In line with this, combined THC-MDMA administration led to synergistic effects on working memory in rats; MDMA in lowto-high doses led to an exacerbation of the THC-induced memory impairment (Young et al. 2005). Interestingly, MDMAinduced memory impairment in rats could be blocked with a $\mathrm{CB}_{1}$ receptor antagonist (Nawata et al. 2010).

Together, these data suggest involvement of the endocannabinoid system in MDMA-induced memory impairment. The present study was therefore set up to study the association between endocannabinoid concentrations and verbal memory performance during MDMA intoxication. It was hypothesized that MDMA would cause an increase in $\mathrm{eCB}$ concentrations together with a decrease in verbal memory performance. In addition, given the role of the 5- $\mathrm{HT}_{2 \mathrm{~A}}$ receptor in memory, and its interaction with the eCB system, it was hypothesized that pretreatment with ketanserin, a $5-\mathrm{HT}_{2 \mathrm{~A}}$ receptor blocker, would counteract the effects of MDMA on endocannabinoid release and memory.

\section{Methods}

\section{Participants}

Participants were 20 healthy polydrug MDMA users (mean (SD) age $=21.2$ (2.6); 8 females), who previously used ecstasy/MDMA (16.8 (23.2) times) and other recreational drugs (e.g., cocaine, amphetamine, and cannabis). The mean (SD) verbal IQ was 103.9 (4.9) as determined by the National
Adult Reading Test on the training session, preceding the test sessions (Bright et al. 2002).

Participants were recruited through advertisements in university buildings, via a website (digi-prik.nl), and by word of mouth.

\section{Design and treatments}

The study was conducted according to a two-by-two doubleblind, placebo-controlled within-subject design with pretreatment (ketanserin $40 \mathrm{mg}$ or placebo) preceding the treatment (MDMA $75 \mathrm{mg}$ or placebo) by $30 \mathrm{~min}$ (Brogden and Sorkin 1990; Sharpley et al. 1994). A double-dummy procedure was used to control for differences in $T_{\max }$ between both drugs. $T_{\max }$ of MDMA is $2 \mathrm{~h}$ (de la Torre et al. 2004) and $T_{\max }$ of ketanserin is between 0.5 and $4 \mathrm{~h}$ (Heykants et al. 1986; Persson et al. 1991; Reimann et al. 1983). The timing of the (pre-) treatment was based on similar research conducted by the same group (van Wel et al. 2011; van Wel et al. 2012) where it was shown that the MDMA-induced elevated mood state was blocked by ketanserin (van Wel et al. 2012).

The 75-mg dose of MDMA was selected because it has consistently been shown to impair memory performance and to produce robust subjective mood changes in a number of previous studies from our lab (Kuypers and Ramaekers 2005, 2007; Kuypers et al. 2016; Ramaekers et al. 2009). Ketanserin 40 mg represents a regular therapeutic dose that blocks $91 \%$ of $5-\mathrm{HT}_{2}$ receptors (Brogden and Sorkin 1990; Sharpley et al. 1994).

A permit for obtaining, storing, and administering MDMA was obtained from the Dutch drug enforcement administration. Randomization of pre-treatment and treatment conditions was generated by means of a Latin square, with each participant being assigned to a treatment sequence.

\section{Procedures}

Prior to participation, all participants were medically assessed by a physician, who examined general health, including an ECG, and who took blood and urine samples for standard chemistry and hematology. In addition, participants were familiarized with the procedures, tests, and questionnaires on a training day, preceding actual test days. On the training day, participants were shown the questionnaires so that they knew what they looked like, and they had to run through all tests so that they understood what was expected. The order of the questionnaires and tests was kept the same as on an actual test day. No learning effects were expected on the tests that were used though parallel versions of the word learning test were used so that each test day participants had to learn a new list and no interference was possible.

Participants were requested to abstain from any drug use 1 week before the medical examination until the last test day. They were asked not to use any caffeinated or alcoholic beverages $24 \mathrm{~h}$ before testing and to get a normal night sleep as assessed with the Groninger Sleep Scale. 
A test day started at 9 am with a screen for drugs of abuse in urine (THC/opiates/cocaine/amphetamines/methamphetamines), a breathalyzer ethanol test, and a pregnancy test for women. When tests were negative, participants had breakfast and a blood sample was taken. At 9:30 am, participants received the pre-treatment followed $30 \mathrm{~min}$ later by the treatment. Participants were then seated in a waiting room. At 11:25 am, a second blood sample was taken. Thereafter, the word learning task was assessed followed by a 1-h test battery consisting of social behavior tests (Approach Avoidance Test with emotional and social situation stimuli, Processing of Sounds Task) and questionnaires (Dissociative Experiences Scale, Clinician Administered Dissociative States Scale, Profile of Mood States); these data are reported elsewhere (Kuypers et al. 2017; Puxty etal. 2017). The test day ended with the collection of a third blood sample. The study consisted of four test days that were minimally separated by a 7-day wash-out period.

The study was performed in accordance with the Helsinki Declaration of 1975, and its subsequent amendments, and was approved by the Medical Ethics Committee of the Academic Hospital of Maastricht and the University of Maastricht. All participants gave their written informed consent after description of the study and they were paid upon completion of the testing periods for their participation.

\section{Word learning task}

The 30-word learning task consists of 30 Dutch mono-syllabic meaningful nouns $(N=18)$ and adjectives $(N=12)$ which are consecutively presented on a computer screen (Kuypers et al. 2013; Rey 1958). The words are either neutral $(N=6)$ or had a valence (positive $(N=12)$ or negative $(N=12))$. The words in the lists of the five parallel versions $(4+1$ for test days + training session) had been matched for abstraction. Participants had to recall verbally as many words as possible (immediate recall). This procedure was repeated three times; immediate scores were summed to comprise the "total immediate recall" score. After a 30-min delay, participants were asked to recall ("delayed recall") as many of the previously learnt words as possible. Hereafter, participants were given a delayed recognition task containing 30 new words and all the words of the previously shown list. Participants' task was to indicate whether the presented word was a new one or one from the original list. Dependent variables were number of correct recalled words per trial, the immediate recall (IR) total score, the delayed recall (DR) score, the delayed recognition score (total number of correct items of the original list; max score $=30$ ), and corresponding RTs.

\section{National Adult Reading Test}

The Dutch version of the National Adult Reading Test was used to estimate the premorbid verbal intelligence of participants (Bright et al. 2002; Schmand et al. 1991).

\section{Groninger Sleep Scale}

The Groninger Sleep Scale assesses sleep quality and quantity (hours of sleep). It consists of 15 dichotomous questions about sleep complaints and an open question concerning the duration of sleep. The number of hours sleep and the total score on this questionnaire were compared over the four test days to ascertain that participants had an equal amount of sleep quantity and quality before each test day (Mulder-Hajonides van der Meulen et al. 1980).

\section{Pharmacokinetics and endocannabinoid concentrations}

Blood samples preserved with EDTA were collected three times on each test day, at baseline, 90 min after treatment, and $150 \mathrm{~min}$ after treatment, in order to determine endocannabinoid (AEA, 2-AG) concentrations and pharmacokinetics of MDMA and ketanserin. Samples were centrifuged immediately and resulting plasma was stored at $20^{\circ} \mathrm{C}$ until analysis.

\section{MDMA and ketanserin blood concentrations}

MDMAwas determined by gas chromatography coupled to mass spectrometry using a method previously described by Pizarro et al. (2002). Ketanserin was determined by liquid chromatography coupled to mass spectrometry. Samples ( $200 \mu \mathrm{L}$ of plasma) were purified with Ostro Pass-through Sample Preparation Plates (Waters, MA, USA) and $600 \mu \mathrm{L}$ of acetonitrile with $0.1 \%$ formic acid was used as the elution solvent. After mixing, vacuum was applied and the collected mixture was evaporated to dryness at $15 \mathrm{psi}$ and $40^{\circ} \mathrm{C}$. Extract was reconstituted with $100 \mu \mathrm{L}$ of ammonium formate $0.02 \%$ at $\mathrm{pH} 5$ and acetonitrile $(50: 50 \mathrm{v} / \mathrm{v})$. Quantification was performed in a HPLC system coupled to a triple-quadrupole (6410 Triple Quad LC-MS; Agilent) mass spectrometer with an electrospray interface. The chromatographic separation was done using a C18 column (Kinetex, $100 \mathrm{~mm} \times$ $3 \mathrm{~mm} \times 1.7 \mu \mathrm{m}$, Phenomenex, CA, USA). The mobile phase was ammonium formate $0.02 \%$ at $\mathrm{pH} 5$ and acetonitrile in an isocratic mode $(50: 50 \mathrm{v} / \mathrm{v})$ at a flow rate of $0.45 \mathrm{~mL} / \mathrm{min}$. All compounds were monitored in positive ionization using the multiple reaction mode mass/charge $(M+1 / z)$. Parameters for the identification of analytes were as follows: ketanserin $396 \rightarrow 146,189,208$; fragmentor (F) $200 \mathrm{~V}$, collision energy (CE) $15 \mathrm{~V}$; and pirenperone $394 \rightarrow 119,159,187$, F200, CE15.

\section{Endocannabinoid concentrations}

The analysis of the endocannabinoids AEA and 2-AG in plasma was performed by a validated method previously described (Pastor et al. 2014). Briefly, aliquots of $0.5 \mathrm{~mL}$ of plasma were transferred to $12-\mathrm{mL}$ glass tubes, spiked with deuterated internal standards, diluted with $0.1 \mathrm{M}$ ammonium 
acetate buffer ( $\mathrm{pH} 4.0$ ), and extracted with tert-butyl methyl ether. The dry organic extracts were reconstituted in $100 \mu \mathrm{L}$ of a mixture water:acetonitrile $(10: 90, v / v)$ with $0.1 \%$ formic acid $(v / v)$ and transferred to HPLC vials. Twenty microliters was injected into the LC/MS-MS system. An Agilent 6410 triple quadrupole (Agilent Technologies, Wilmington, DE, USA) equipped with a 1200 series binary pump, a column oven, and a cooled auto-sampler $\left(4{ }^{\circ} \mathrm{C}\right)$ was used. Chromatographic separation was carried out with a ACQUITY UPLC C18-CSH column $(3.1 \times 100 \mathrm{~mm}$, $1.8 \mu \mathrm{m}$ particle size) (Waters, Yvelines Cedex, France) maintained at $40{ }^{\circ} \mathrm{C}$ with a mobile phase flow rate of $0.4 \mathrm{~mL} / \mathrm{min}$. The composition of the mobile phase was as follows: A: $0.1 \%$ $(v / v)$ formic acid in water; B: $0.1 \%(v / v)$ formic acid in acetonitrile. Detection was done by selection reaction monitoring (SRM). Quantification was performed by isotope dilution. Deuterated internal standards were obtained from Cayman Chemical (Ann Arbor, MI, USA), and solvents were from Merck (Darmstadt, Germany).

\section{Statistical analysis}

Data of the word learning task (WLT) and the concentrations of eCBs entered a general linear model (GLM) repeated measures ANOVA (SPSS, version 24.0) with pre-treatment (two levels: ketanserin, placebo) and treatment (two levels: MDMA, placebo) as main within-subject factors. IR trial (three levels) was included as extra within-subject factor for the WLT. Data of the Groninger Sleep Scale (sleep quantity and sleep quality) entered repeated measures ANOVA with test day (four levels) as within-subject factor to test whether participants had an equal amount of sleep quantity and quality before each test day.

Paired sample $t$ tests were conducted to investigate the difference in MDMA and ketanserin concentrations in conditions where MDMA or ketanserin was administered alone and in combination.

The alpha criterion level of statistical significance for all analyses was set at $p=0.05$. Partial eta squared (partial $\eta^{2}$ ) is reported in case of significant effects to demonstrate the effect's magnitude, where 0.01 is defined as small, 0.06 as moderate, and 0.14 as large. Partial eta squared is based on Cohen's $f$ which defines small, medium, and large as, respectively, $0.10,0.25$, and 0.50 which corresponds to $\eta^{2}$ of 0.0099 , 0.0588 , and 0.1379 (Richardson 2011).

\section{Results}

\section{Word learning task}

GLM RM ANOVA analysis revealed a main effect of treatment on immediate recall total $\left(F_{1,19}=5.48, p=0.03\right.$, partial $\left.\eta^{2}=0.22\right)$. There was also a main effect of trial on immediate recall (IR) per trial indicating that performance increased over trials $\left(F_{1,19}=91.02, p<0.001\right.$, partial $\left.\eta^{2}=0.83\right)$. Under influence of MDMA, participants recalled on average 1.6 words less per trial, and in total 4.8 words less, compared to placebo. Analysis also revealed a main effect of treatment $\left(F_{1,19}=\right.$ 8.76, $p=0.008$, partial $\eta^{2}=0.32$ ) on delayed recall (DR). Participants recalled on average 3 words less, 30 min after the initial learning phase, compared to placebo. There was no main effect of pre-treatment or valence, or an interaction effect between factors. There was no main effect of pretreatment or an interaction effect of pre-treatment by treatment on IR trial, IR total, or DR (Fig. 1a).

Analysis revealed no statistically significant main effect of treatment, pre-treatment, or their interaction on number of correct recognized words (Fig. 1b). A main effect of pretreatment $\left(F_{1,19}=5.94, p=0.02\right.$, partial $\left.\eta^{2}=0.24\right)$ was found on reaction time related to correct recognized words. Participants were on average $49 \mathrm{~ms}$ slower under influence of ketanserin compared to placebo (Fig. 1c). There was no main effect of treatment or pre-treatment by treatment interaction on reaction time in the recognition task.

\section{Groninger Sleep Scale}

Analysis of the Groninger Sleep Scale, which served as a control measure, showed no difference in sleep quality $\left(F_{3}\right.$, ${ }_{57}=2.11, p=0.11$, partial $\left.\eta^{2}=0.10\right)$ and quantity $\left(F_{3,57}=\right.$ $0.35, p=0.79$, partial $\eta^{2}=0.02$ ) between the four test days. Participants slept on average $6 \mathrm{~h}$ and $59 \mathrm{~min}(\mathrm{SD}=0.9)$ on the night prior to a test day, and they had and average sleep quality score of $2.5(\mathrm{SD}=2.3)$.

\section{Pharmacokinetics and endocannabinoid concentrations}

\section{Endocannabinoid concentrations}

Analyses revealed a main effect of pre-treatment $\left(F_{1,11}=10.6\right.$; $p=0.005$; $\operatorname{partial} \eta^{2}=0.41$ ) on plasma AEA concentrations (ng/ $\mathrm{mL}$ ) assessed after the tests. AEA concentrations were higher $180 \mathrm{~min}$ after ketanserin administration compared to placebo. There were no differences in endocannabinoid (2-AG, AEA) plasma concentrations at baseline and there were no other main or interaction effects on 2-AG or AEA concentrations (Fig. 2).

Since visual inspection of the data suggested differences between baseline concentrations of 2-AG and AEA, and the two subsequent measurements, before and after the cognitive tests, an extra explorative GLM was run to test whether endocannabinoid concentrations varied naturally over time. The extra GLM demonstrated a main effect of "measurement" on 2-AG $\left(F_{2,30}=\right.$ 15.90; $p<0.001$; partial $\left.\eta^{2}=0.51\right)$ and AEA concentrations $\left(F_{2,30}=13.90 ; p<0.001\right.$; partial $\left.\eta^{2}=0.47\right)$. Pairwise comparisons revealed that $2-\mathrm{AG}$ baseline concentrations were 


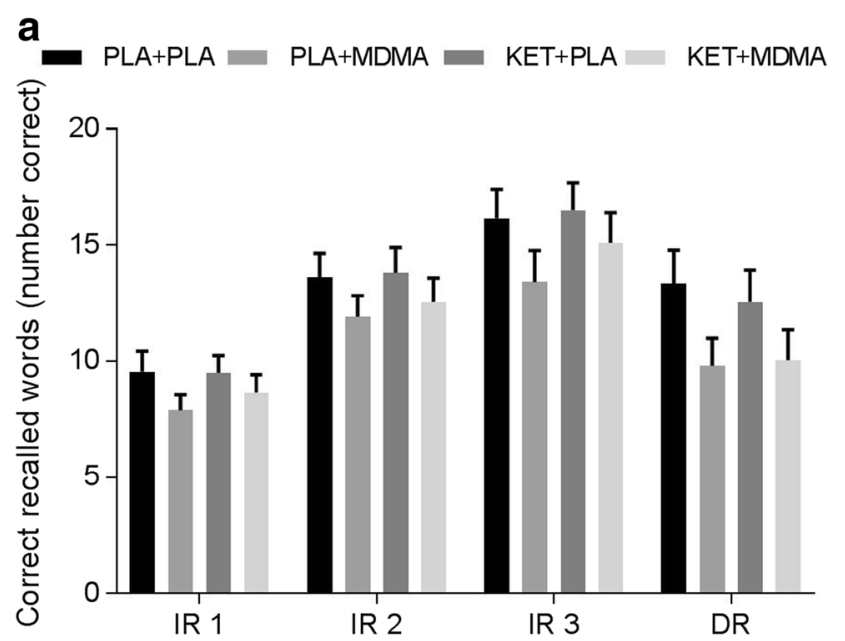

b

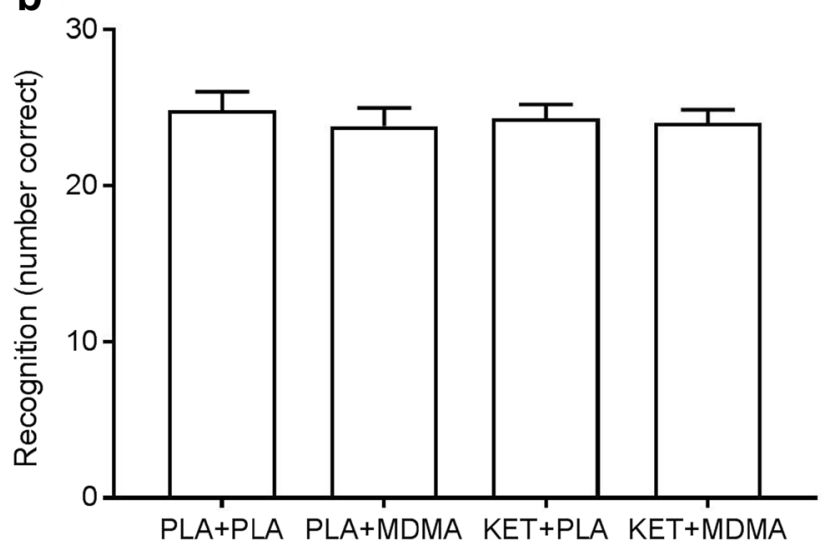

C

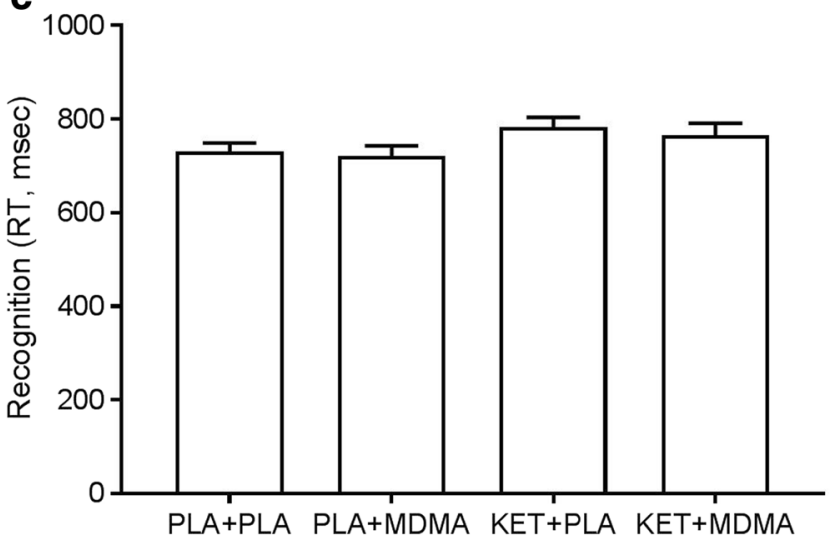

Fig. 1 Mean (SE) of number correct recalled words (a), number of correct recognized words (b), and corresponding reaction times $(\mathbf{c})$ in the word learning task per treatment condition. PLA placebo, KET ketanserin

significantly lower compared to measure 2 (before cognitive tests) and measure 3 (after cognitive tests); 2-AG concentrations did not statistically differ between measurements 2 and 3 . Baseline AEA concentrations were significantly lower compared to the second measurement while there were no differences between baseline concentrations and the third measure or between the second and the third measure.

\section{MDMA and ketanserin blood concentrations}

Paired sample $t$ tests showed that MDMA plasma concentrations $(\mathrm{ng} / \mathrm{mL})$ did not statistically differ between the MDMA alone condition (mean $( \pm \mathrm{SE})$ : 90 min post-MDMA: 134.8 (16.6); 150 min post-MDMA: 186.0 (17.7)) and the condition where MDMA was combined with ketanserin (mean $( \pm \mathrm{SE})$ : 90 min post-MDMA: 126.7 (15.1); 150 min post-MDMA: 182.9 (14.7)). The same was shown for ketanserin plasma concentrations $(\mathrm{ng} / \mathrm{mL})$ that did not differ between the ketanserin alone condition (mean $( \pm \mathrm{SE})$ : 90 min postMDMA: 54.9 (7.6); 150 min post-MDMA: 64.5 (6.0)) and the condition where ketanserin was combined with MDMA (mean ( \pm SE): 90 min post-MDMA: $59.0(8.8) ; 150$ min postMDMA: 61.5 (5.4)).

\section{Discussion}

The aim of the present study was to investigate the neurobiological mechanism underlying memory impairment during MDMA intoxication. Based on previous research, it was hypothesized that MDMA would cause an increase in eCB concentrations together with a decrease in memory performance. In addition, it was hypothesized that the combination of MDMA and a 5- $\mathrm{HT}_{2 \mathrm{~A}}$ receptor blocker, ketanserin, would counteract this endocannabinoid release and the memory deficit. Findings showed that MDMA caused memory impairment in the verbal word learning task. This effect was a replication of previous studies using the same dose of MDMA (75 mg) and the same learning paradigm (Kuypers et al. 2016; Kuypers and Ramaekers 2005). Contrary to our hypothesis, MDMA did not affect eCB concentrations nor did ketanserin block the MDMA-induced memory impairment. Ketanserin caused an increase in AEA concentrations, 180 min after administration.

While preclinical studies have shown an elevation in eCB concentrations (Braida et al. 2005; Braida and Sala 2002), the present study did not demonstrate a significant increase in plasma $\mathrm{eCB}$ concentrations in healthy recreational drug users after a single dose of MDMA. This absence of MDMA effects on eCB concentrations could potentially be attributed to the difference in dosing and dosing schemes with "extreme" dose and dosing schemes in preclinical research exceeding "normal" dose ranges in humans (Easton and Marsden 2006; Green et al. 2012). In the study of Nawata and colleagues for example, endocannabinoid concentrations were elevated in mice after treatment with MDMA for seven subsequent days. The resulting memory impairment was reversed by a $\mathrm{CB}_{1}$ antagonist (Nawata et al. 2010). The MDMAinduced memory impairment which has consistently been demonstrated in human placebo-controlled studies seems to be unrelated to the endocannabinoid system. 
a

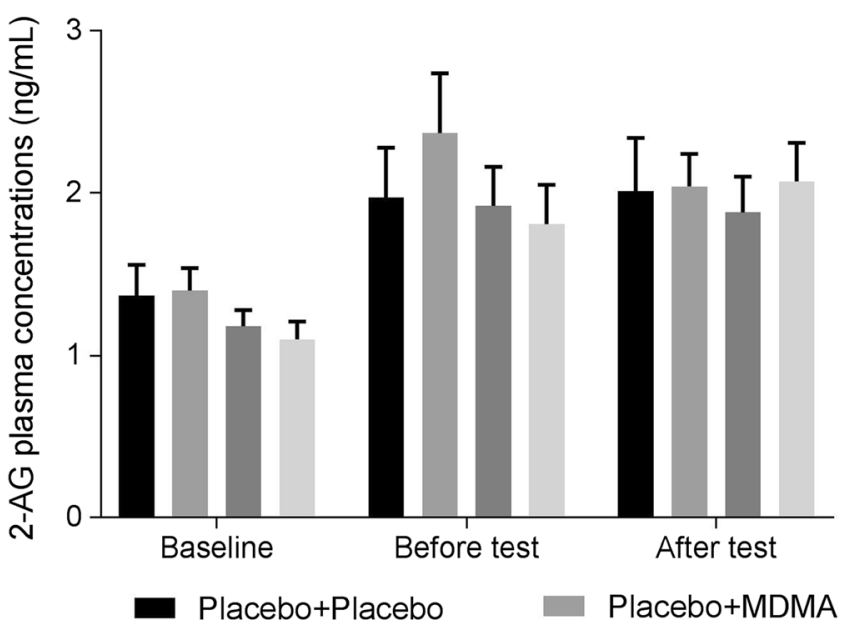

b

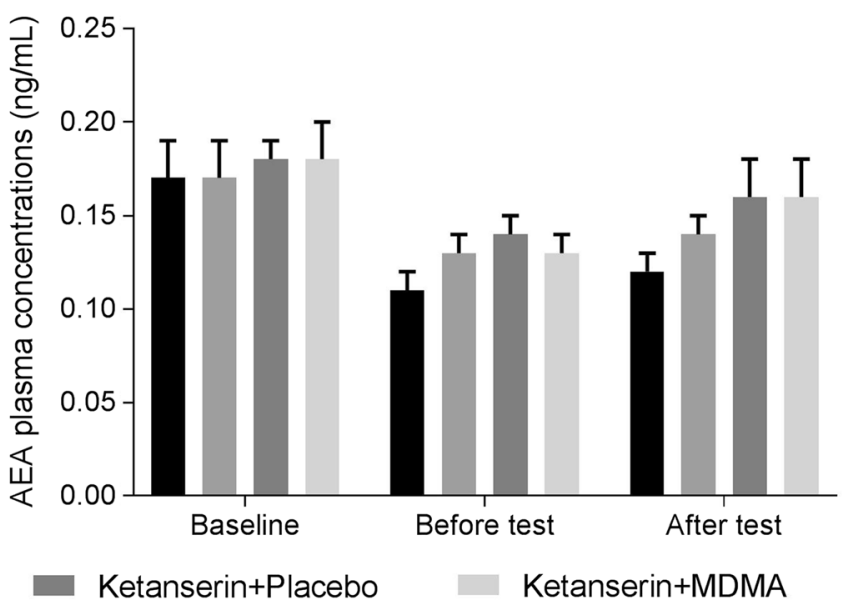

Fig. 2 Mean $( \pm$ SE) plasma concentrations of 2-AG (a) and AEA (b) in the four treatment conditions, and at baseline, before tests $(90$ min after treatment, respectively, $120 \mathrm{~min}$ after pre-treatment), and after tests (150 min after treatment, respectively, 180 min after pre-treatment)

The fact that endocannabinoid concentrations in the present study were assessed at the peripheral level, in blood plasma, could be another potential explanation for the absence of MDMA effects on eCB concentrations. It is possible that peripheral eCB concentrations might not reflect central concentrations accurately and preclinical work has previously shown that $\mathrm{AG}$ and AEA concentrations measured at the peripheral (plasma) and central level (cerebrospinal fluid (CSF)) did not correlate significantly (Jumpertz et al. 2011). While assessing biological parameters at the central level by drawing CSF is invasive, it is very relevant to conduct these measures and to compare central and peripheral markers in a placebocontrolled MDMA study prior to conducting behavioral studies. This information could fine-tune and optimize the timing and scheduling of tests.

While an MDMA effect on eCB concentrations was absent, data of the 2-AG and AEA concentrations, measured at three different time points, suggested time-related differences in concentrations. This motivated an extra statistical analysis including the three time points (9:00 am, 11:30 am, and $12: 30 \mathrm{pm}$ ). It was shown that 2-AG concentrations increased during the test day and relative to baseline, and that AEA concentrations decreased. Interestingly, preclinical work has shown that endocannabinoids have a diurnal release pattern which is opposite to 2-AG and AEA, with higher AEA concentrations in a selection of brain areas (nucleus accumbens, prefrontal cortex, striatum, and hippocampus) in the dark or "active" phase and high concentrations for 2-AG during the light or "resting" phase (Valenti et al. 2004). Although this pattern in rats is opposite to our findings, the fact that eCBs have a diurnal rhythm is interesting. Human research has also shown that eCBs have a specific rhythm and our data are in line with this, with continuously increasing 2-AG concentrations across the morning, peaking in the early- to mid- afternoon, and decreasing AEA concentrations during the day (Hanlon et al. 2015; Vaughn et al. 2010).

Preclinical studies have in addition also shown that eCB concentrations do not only fluctuate over time but display different release patterns in different brain locations, showing for example higher AEA concentrations during resting phases in CSF and hypothalamus, while these concentrations are low in other brain structures like the hippocampus and the prefrontal cortex, both known to play a role in memory (MurilloRodriguez et al. 2006). In addition, preclinical research has demonstrated that AEA plays a central role in memory consolidation, while 2-AG does not (Busquets-Garcia et al. 2011). The relation between AEA concentrations and $\mathrm{CB}_{1}$ receptor density is out of phase and dependent on time of day. In the resting phase, a high $\mathrm{CB}_{1}$ receptor density together with low AEA concentrations is found in the hippocampus while this pattern is reversed when the animals are awake and active (Vaughn et al. 2010). Together, these results suggest that it is relevant to test memory during the morning, when AEA concentrations are high in humans, in addition to other times of the day, when AEA concentrations are lower, and assess the expression of the $\mathrm{CB}_{1}$ receptor, in a placebo-controlled MDMA study in order to know whether diurnal variations in AEA and $\mathrm{CB}_{1}$ receptor influence or change the MDMAinduced memory deficit.

Research into the role of eCBs in the MDMA-induced memory deficit in humans is limited by the absence of approved $\mathrm{CB}_{1}$ antagonists. Rimonabant, a $\mathrm{CB}_{1}$ receptor antagonist/inverse agonist, which was approved for weight control, was withdrawn from the market, in addition to a suspension of its development, after some adverse clinical psychiatric side effects (Janero and Makriyannis 2009). Another approach to this problem is to administer THC, a partial $\mathrm{CB}_{1}$ and $\mathrm{CB}_{2}$ agonist, or a fatty acid amide hydroxylase (FAAH) 
inhibitor, an enzyme involved in the catabolism of AEA, and MDMA in combination, since both combinations suggestible lead to an increase in endocannabinoid concentrations (Gobbi et al. 2005; Pertwee 1997). In animal research, a synergistic disruptive effect of the THC-MDMA combination was shown on memory (Young et al. 2005). One human study combining THC with MDMA did not show a change in the drug-induced memory effect of the single drugs on an N-back task (working memory). Interestingly, the subjective effects (e.g., drug strength, feeling high) did increase after the combined administration (Dumont et al. 2011). Interestingly, animal research has shown that order is important in these effects. While dopamine concentrations decreased when MDMA was given prior to THC, this change was not present when THC was given before MDMA (Robledo et al. 2007). In the study of Dumont et al. (2011), the first dose of THC (4 mg) was given concurrently with MDMA (100 mg), while the two subsequent doses of each $6 \mathrm{mg}$ followed MDMA administration by 90 and $180 \mathrm{~min}$. Future research could compare the effects of pre- and post-dosing MDMA-treated participants with THC to explore the order effects of the different treatments and reveal whether the effect on $\mathrm{eCB}$ concentrations relates to substance-induced memory impairment.

Although ketanserin exerted effects on the behavioral and biological level in the present study, inducing a response speed reduction in the word recognition task and causing an increase in AEA concentrations, it did not counteract the MDMA-induced memory impairment (immediate recall) which is in contrast to a previous study conducted by our group (van Wel et al. 2011). Findings of a previous study using the same dose $(40 \mathrm{mg})$ of ketanserin suggest that this dose is sufficient to block the $5-\mathrm{HT}_{2}$ receptor and potential subjective and/or behavioral effects caused by a serotonergic substance (Vollenweider et al. 1998). However, van Wel etal. (2011) used a 50-mg dose and showed a blockade of the MDMA-induced memory impairment. This $22 \%$ difference in dose resulted in ketanserin plasma concentrations that were 1.5 times lower than in the previous study. Scrutinizing behavioral data of both studies, it became apparent that memory performance during placebo ("baseline") was comparable though the MDMA-induced impairment, relative to placebo, was larger in the study of van Wel et al. (2011). Performance in the latter study decreased with $29 \%$ compared to a $16 \%$ decrease in the present study. This apparent smaller decrease in memory performance after MDMA administration in the present study could potentially be attributed to the MDMA concentrations that were $20 \%$ lower. Previously, it was shown that MDMA-induced memory failures correlated positively with MDMA blood concentrations (Ramaekers et al. 2009). When MDMA was combined with ketanserin, the MDMA-induced decrease in memory performance was reduced with $15 \%$ while this was only $8 \%$ in the present study. This smaller "gain" in memory performance could then perhaps be attributed to the lower availability of ketanserin and hence a potentially smaller blockade of the $5-\mathrm{HT}_{2}$ receptors.
While behavioral and biological data showed some effects of ketanserin, proving that it had effects on the central level, these low concentrations in blood were possibly not strong enough to counteract the MDMA-induced memory impairment.

To conclude, current findings suggest that peripheral endocannabinoids are not related to verbal memory impairment during MDMA intoxication.

Acknowledgements The authors would like to thank Cees van Leeuwen for the medical supervision and Tina Verstappen and Sido van Berlo for collecting the data.

Author contribution KK, JR, MF, and RdlT conceptualized the study; KK collected data; $\mathrm{EH}, \mathrm{AP}, \mathrm{EO}, \mathrm{NP}$, and KK analyzed the data; and $\mathrm{EH}$, MF, RdlT, JR, and KK wrote the article.

Compliance with ethical standards The study was performed in accordance with the Helsinki Declaration of 1975, and its subsequent amendments, and was approved by the Medical Ethics Committee of the Academic Hospital of Maastricht and the University of Maastricht. All participants gave their written informed consent after description of the study and they were paid upon completion of the testing periods for their participation.

Conflict of interest This research was funded by the Netherlands Organization for Scientific Research (NWO), Grant Number: 400-072013, awarded to JR and KK. The work was supported by grants from DIUE de la Generalitat de Catalunya (2014SGR 680).

Open Access This article is distributed under the terms of the Creative Commons Attribution 4.0 International License (http:// creativecommons.org/licenses/by/4.0/), which permits unrestricted use, distribution, and reproduction in any medium, provided you give appropriate credit to the original author(s) and the source, provide a link to the Creative Commons license, and indicate if changes were made.

\section{References}

Braida D, Sala M (2002) Role of the endocannabinoid system in MDMA intracerebral self-administration in rats. British Journal of Pharmacology 136(8):1089-1092. https://doi.org/10.1038/sj.bjp. 0704825

Braida D, Iosuè S, Pegorini S, Sala M (2005) 3,4Methylenedioxymethamphetamine-induced conditioned place preference (CPP) is mediated by the endocannabinoid system. Pharmacological Research 51(2):177-182. https://doi.org/10.1016/ j.phrs.2004.07.009

Bright P, Jaldow E, Kopelman MD (2002) The National Adult Reading Test as a measure of premorbid intelligence: a comparison with estimates derived from demographic variables. Journal of the International Neuropsychological Society : JINS 8(6):847-854. https://doi.org/10.1017/S1355617702860131

Brogden RN, Sorkin EM (1990) Ketanserin. Drugs 40(6):903-949. https://doi.org/10.2165/00003495-199040060-00010

Busquets-Garcia A, Puighermanal E, Pastor A, de la Torre R, Maldonado R, Ozaita A (2011) Differential role of anandamide and 2arachidonoylglycerol in memory and anxiety-like responses. Biological Psychiatry 70(5):479-486. https://doi.org/10.1016/j. biopsych.2011.04.022 
Curran HV, Freeman TP, Mokrysz C, Lewis DA, Morgan CJ, Parsons LH (2016) Keep off the grass? Cannabis, cognition and addiction. Nat Rev Neurosci 17(5):293-306. https://doi.org/10.1038/nrn.2016.28

Dumont GJ, van Hasselt JG, de Kam M, van Gerven JM, Touw DJ, Buitelaar JK, Verkes RJ (2011) Acute psychomotor, memory and subjective effects of MDMA and THC co-administration over time in healthy volunteers. Journal of psychopharmacology (Oxford, England) 25(4):478-489. https://doi.org/10.1177/ 0269881110376687

Easton N, Marsden CA (2006) Ecstasy: are animal data consistent between species and can they translate to humans? J Psychopharmacol 20(2):194-210. https://doi.org/10.1177/0269881106061153

Erritzoe D et al (2011) In vivo imaging of cerebral serotonin transporter and serotonin(2A) receptor binding in 3,4methylenedioxymethamphetamine (MDMA or "ecstasy") and hallucinogen users. Arch Gen Psychiatr 68:562-576. https:// doi.org/10.1001/archgenpsychiatry.2011.56

Gobbi G et al (2005) Antidepressant-like activity and modulation of brain monoaminergic transmission by blockade of anandamide hydrolysis. Proc Nat Acad Sci U S A 102:18620-18625. https://doi.org/10. 1073/pnas.0509591102

Green AR, King MV, Shortall SE, Fone KCF (2012) Lost in translation: preclinical studies on 3,4-methylenedioxymethamphetamine provide information on mechanisms of action, but do not allow accurate prediction of adverse events in humans. Br J Pharmacol 166:15231536. https://doi.org/10.1111/j.1476-5381.2011.01819.x

Haj-Dahmane S, Shen R-Y (2011) Modulation of the serotonin system by endocannabinoid signaling. Neuropharmacology 61:414-420. https://doi.org/10.1016/j.neuropharm.2011.02.016

Hanlon EC, Tasali E, Leproult R, Stuhr KL, Doncheck E, de Wit H, Hillard CJ, van Cauter E (2015) Circadian rhythm of circulating levels of the endocannabinoid 2-arachidonoylglycerol. J Clin Endocrinol Metab 100(1):220-226. https://doi.org/10.1210/jc. 2014-3455

Heykants J, Van Peer A, Woestenborghs R, Gould S, Mills J (1986) Pharmacokinetics of ketanserin and its metabolite ketanserin-ol in man after intravenous, intramuscular and oral administration. Eur J Clin Pharmacol 31:343-350. https://doi.org/10.1007/bf00981135

Janero DR, Makriyannis A (2009) Cannabinoid receptor antagonists: pharmacological opportunities, clinical experience, and translational prognosis. Expert Opin Emerg Drugs 14:43-65. https://doi.org/10. $1517 / 14728210902736568$

Jumpertz R, Guijarro A, Pratley RE, Piomelli D, Krakoff J (2011) Central and peripheral endocannabinoids and cognate Acylethanolamides in humans: association with race, adiposity, and energy expenditure. J Clin Endocrinol Metab 96(3):787-791. https://doi.org/10.1210/jc. 2010-2028

Kuypers KPC, Ramaekers JG (2005) Transient memory impairment after acute dose of $75 \mathrm{mg}$ 3.4-methylenedioxymethamphetamine. J Psychopharmacol 19(6):633-639. https://doi.org/10.1177/ 0269881105056670

Kuypers KPC, de la Torre R, Farre M, Pujadas M, Ramaekers JG (2013) Inhibition of MDMA-induced increase in cortisol does not prevent acute impairment of verbal memory. British Journal of Pharmacology 168(3):607-617. https://doi.org/10.1111/j.14765381.2012.02196.x

Kuypers KP, Theunissen e1, van Wel JH, de Sousa Fernandes Perna EB, Linssen A, Sambeth A, Schultz BG, Ramaekers JG (2016) Verbal memory impairment in polydrug ecstasy users: a clinical perspective. PloS One 11(2):e0149438. https://doi.org/10.1371/journal. pone. 0149438

Kuypers KPC, de la Torre R, Farre M, Pizarro N, Xicota L, Ramaekers JG (2017) MDMA-induced indifference to negative sounds is mediated by the 5-HT2A receptor Psychopharmacology (Berl). https://doi. org/10.1007/s00213-017-4699-1
Mulder-Hajonides van der Meulen WREH, Wijnberg JR, Hollanders JJ, De Diana I, Hoofdakker R (1980) Measurement of subjective sleep quality. Paper presented at the Fifth European Congress on Sleep Research, Amsterdam

Murillo-Rodriguez E, Desarnaud F, Prospero-Garcia O (2006) Diurnal variation of arachidonoylethanolamine, palmitoylethanolamide and oleoylethanolamide in the brain of the rat. Life Sci 79:30-37. https:// doi.org/10.1016/j.lfs.2005.12.028

Nawata Y, Hiranita T, Yamamoto T (2010) A cannabinoid CB(1) receptor antagonist ameliorates impairment of recognition memory on withdrawal from MDMA (ecstasy). Neuropsychopharmacology 35: 515-520. https://doi.org/10.1038/npp.2009.158

Parrish JC, Nichols DE (2006) Serotonin 5-HT(2A) receptor activation induces 2-arachidonoylglycerol release through a phospholipase cdependent mechanism. J Neurochem 99:1164-1175. https://doi.org/ 10.1111/j.1471-4159.2006.04173.x

Pastor A, Farré M, Fitó M, Fernandez-Aranda F, de la Torre R (2014) Analysis of ECs and related compounds in plasma: artifactual isomerization and ex vivo enzymatic generation of 2-MGs. J Lipid Res 55:966-977. https://doi.org/10.1194/jlr.D043794

Persson B, Heykants J, Hedner T (1991) Clinical pharmacokinetics of ketanserin. Clinical Pharmacokinetics 20(4):263-279. https://doi. org/10.2165/00003088-199120040-00002

Pertwee RG (1997) Pharmacology of cannabinoid CB1 and CB2 receptors. Pharmacol Ther 74:129-180. https://doi.org/10.1016/S01637258(97)82001-3, 2

Pizarro N, Ortuno J, Farre M, Hernandez-Lopez C, Pujadas M, Llebaria A, Joglar J, Roset PN, Mas M, Segura J, Cami J, de la Torre R (2002) Determination of MDMA and its metabolites in blood and urine by gas chromatography-mass spectrometry and analysis of enantiomers by capillary electrophoresis. J Anal Toxicol 26(3): 157-165. https://doi.org/10.1093/jat/26.3.157

Puxty DJ, Ramaekers JG, de la Torre R, Farré M, Pizarro N, Pujadas M, Kuypers KPC (2017) MDMA-induced dissociative state not mediated by the 5-HT2A receptor. Front Pharmacol Neuropharmacol 8(455). https://doi.org/10.3389/fphar.2017.00455

Ramaekers JG, Kuypers KPC, Wingen M, Heinecke A, Formisano E (2009) Involvement of inferior parietal lobules in prospective memory impairment during acute MDMA (Ecstasy) intoxication: an event-related fMRI study. Neuropsychopharmacol Off Publ Am Coll Neuropsychopharmacol 34(7):1641-1648. https://doi.org/10. 1038/npp.2008.219

Reimann IW, Okonkwo PO, Klotz U (1983) Pharmacokinetics of ketanserin in man. Eur J Clin Pharmacol 25(1):73-76. https://doi. org/10.1007/bf00544018

Rey A (1958) The clinical examination in psychology/L'examen clinique en psychologie. Presses Universitaires De France, Paris

Richardson JTE (2011) Eta squared and partial eta squared as measures of effect size in educational research. Educ Res Rev 6:135-147. https:// doi.org/10.1016/j.edurev.2010.12.001

Robledo P, Trigo JM, Panayi F, de la Torre R, Maldonado R (2007) Behavioural and neurochemical effects of combined MDMA and THC administration in mice. Psychopharmacology 195(2):255264. https://doi.org/10.1007/s00213-007-0879-8

Schmand B, Bakker D, Saan R, Louman J (1991) De Nederlandse Leestest voor Volwassenen: een maat voor het premorbide intelligentieniveau. Tijdschrift voor Gerontologie en Geriatrie 22: $15-19$

Sharpley AL, Elliott JM, Attenburrow MJ, Cowen PJ (1994) Slow wave sleep in humans: role of 5-HT2A and 5-HT2C receptors. Neuropharmacology 33:467-471. https://doi.org/10.1016/00283908(94)90077-9

de Sousa Fernandes Perna EB, Theunissen EL, Kuypers KPC, Heckman P, de la Torre R, Farre M, Ramaekers JG (2014) Memory and mood during MDMA intoxication, with and without memantine 
pretreatment. Neuropharmacology 87:198-205. https://doi.org/10. 1016/j.neuropharm.2014.03.008

de la Torre R, Farré M, Roset PN, Pizarro N, Abanades S, Segura M, Segura J, Camí J (2004) Human pharmacology of MDMA: pharmacokinetics, metabolism, and disposition. Ther Drug Monit 26(2): 137-144. https://doi.org/10.1097/00007691-200404000-00009

Valenti M, Viganò D, Casico MG, Rubino T, Steardo L, Parolaro D, Di Marzo V (2004) Differential diurnal variations of anandamide and 2-arachidonoyl-glycerol levels in rat brain. Cell Mol Life Sci CMLS 61:945-950. https://doi.org/10.1007/s00018-003-3453-5

Valverde O, Rodriguez-Arias M (2013) Modulation of 3,4methylenedioxymethamphetamine effects by endocannabinoid system. Curr Pharm Des 19(40):7081-7091. https://doi.org/10.2174/ 138161281940131209144331

Vaughn LK, Denning G, Stuhr KL, Hd W, Hill MN, Hillard CJ (2010) Endocannabinoid signalling: has it got rhythm? Br J Pharmacol 160(3):530-543. https://doi.org/10.1111/j.1476-5381.2010.00790.x
Vollenweider FX, Vollenweider-Scherpenhuyzen MF, Bäbler A, Vogel H, Hell D (1998) Psilocybin induces schizophrenia-like psychosis in humans via a serotonin-2 agonist action. Neuroreport 9(17):38973902. https://doi.org/10.1097/00001756-199812010-00024

van Wel JHP, Kuypers KPC, Theunissen EL, Bosker WM, Bakker K, Ramaekers JG (2011) Blockade of 5-HT2 receptor selectively prevents MDMA induced verbal memory impairment. Neuropsychopharmacology 36:1932-1939. https://doi.org/10. 1038/npp.2011.80

van Wel JHP, Kuypers KPC, Theunissen EL, Bosker WM, Bakker K, Ramaekers JG (2012) Effects of acute MDMA intoxication on mood and impulsivity: role of the 5-HT2 and 5-HT1 receptors. PLoS One 7:e40187. https://doi.org/10.1371/journal.pone.0040187

Young JM, McGregor IS, Mallet PE (2005) Co-administration of THC and MDMA ('ecstasy') synergistically disrupts memory in rats. Neuropsychopharmacology 30(8):1475-1482. https://doi.org/10. 1038/sj.npp.1300692 